\title{
Thermodynamic Study of Intermediate State of Papain Induced by n-Alkyl Sulfates at Two Different pH Values: A Spectroscopic Approach
}

\author{
J. Chamani ${ }^{*},{ }^{1}$, M. Heshmati ${ }^{1}$, O. Rajabi ${ }^{2}$ and K. Parivar ${ }^{3}$ \\ ${ }^{I}$ Department of Biology, Faculty of Science, Islamic Azad University-Mashhad Branch, Mashhad, Iran \\ ${ }^{2}$ Department of Pharmacy, Campus of Ferdowsi University, Mashhad, Iran \\ ${ }^{3}$ Department of Biology, Faculty of Science, Islamic Azad University-Science and Research Branch, Tehran, Iran
}

\begin{abstract}
The formation of the intermediate state of papain was induced by n-alkyl sulfates including sodium octyl sulfate, SOS; sodium decyl sulfate, SDeS; and sodium dodecyl sulfate, SDS at different concentrations. A systematic investigation of n-alkyl sulfates induced conformational alteration in molten globule state under an acidic condition and the native state of papain was examined by tryptophan fluorescence, 1-anilino 8-naphtalene sulfonic acid (ANS) binding and UV absorbance. The addition of n-alkyl sulfates to molten globule state at $\mathrm{pH} 2$ shows a decrease in tryptophan fluorescence intensity and quenched ANS fluorescence relative to the native state that leads to enhancement in tryptophan fluorescence and an increase in ANS fluorescence as well. In the presence of $n$-alkyl sulfates in various conditions, two intermediate $\left(\mathrm{I}_{\mathrm{A}}\right.$ and $\left.\mathrm{I}_{\mathrm{B}}\right)$ with different conformations were obtained at acidic and native states, respectively. Thus, we can assume that the intermediate states in folding and unfolding pathways in various conditions have different structures. The results show that SDS is much more effective than SDeS and SOS for the formation of the intermediate states for papain in the two different pathways due to the presence of its hydrophobic tail. Therefore, hydrophobic interactions play an important role in inducing the two different intermediates along the two various thermodynamic pathways.
\end{abstract}

Keywords: Papain, n-Alkyl sulfates, intermediate state, thermodynamic, refolding, unfolding.

\section{INTRODUCTION}

The globular protein, papain (EC.3.4.22.2) is a thiol enzyme from the latex and unripe fruit of carica papaya (tropical melon or pawpaw). The cystein protease, papain is unusually resistant to high temperatures and to high concentrations of denaturing agents, such as, $8 \mathrm{M}$ urea or organic solvent like $70 \%$ EtOH $[1,2]$. Papain is a carbohydrate free, basic, single chain protein. Papain has a molecular weight of 23,000 Da and consists of 212 amino acid residues (metionin absents; IP 8.7) with four disulfide bridges and catalytically important cystein (position 25) and histidin residues (position 158) [3, 4].

The study of the folding intermediates and denatured states provides an insight to understanding how and when various forces come to play their roles in the folding process of the protein $[5,6]$. The development of a broad range of techniques has led to the identification and characterization of stable folding intermediates, termed "molten globule", (MG) which have been shown to be compact structures with a pronounced secondary structure which lack rigid tertiary structures [7-10]. Recent evidence, however, supports the idea that the molten globules may also possess well-defined tertiary contacts [11-14]. At $\mathrm{pH} 2$, a papain exhibit substantial secondary structure as $\beta$-sheet and is relatively less denatured compared to $6 \mathrm{M}$ guanidium hydrochloride $(\mathrm{GnHCl})$ but loses the persistent tertiary structure of the native state [15]. The addition of HFIP and TFE caused an induction of $\alpha$-helical structure as evident from the increase in the mean residue ellipticity value at 208 and $222 \mathrm{~nm}$. In

*Address correspondence to this author at the Department of Biology, Faculty of Science, Islamic Azad University-Mashhad Branch, Mashhad, Iran; Tel: + 98511 8435050; Fax: + 985118435050 ;

E-mail: chamani@ibb.ut.ac.ir addition tryptophan fluorescence studies indicate a change in the environment of the tryptophan residues on the addition of HFIP and TFE to MG state of papain. Maximum ANS binding occurs at 13\%(V/V) HFIP and 30\% (V/V) TFE, suggesting a compact "molten globule" - like conformation with enhanced exposure of hydrophobic surface area [16]. In the molten globule state $(\mathrm{pH} 2)$, papain shows a great tendency to aggregate at lower concentrations of $\mathrm{GnHCl}$ or a high concentration of salt $[17,18]$. Also, the conformational behavior of papain in aqueous solution has been investigated in the presence of SDS. The results show the high $\alpha$-helical content and unfolded structure of papain in the presence of SDS is due to strong electrostatic repulsion [19]. In this paper we have reported for the first time that there are different structures of intermediate states with various stability under acidic and native conditions in the presence of $n$-alkyl sulfates along papain denaturation pathway.

\section{MATERIALS AND METHODS}

\subsection{Materials}

Fresh latex from green fruits of Carica papaya was collected and immediately transported in ice path to the lab, papain was isolated by anionic exchange chromatography on a column of Diethylaminoethyl sepharos 6B Purity, and homogeneity of the preparation was checked by SDSpolyacrilamide gel electrophoresis [20-22] (Fig. 1). To avoid any hindrance due to the autolytic nature of papain, the cystein was blocked by carboxymethylation [23]. Such a blocked protein is similar to the active form in all its physical properties. Therefore, for all the studies presented here, such inactive protein (1RCM-papain) was used. An extinction coefficient of $\varepsilon 1 \%=25$ was used for the determination of concentration of papain solutions [24]. Sodium octyl sulfate (SOS) and sodium dodecyl sulfate (SDS) were purchased from Sigma. Sodium decyl sulfate 


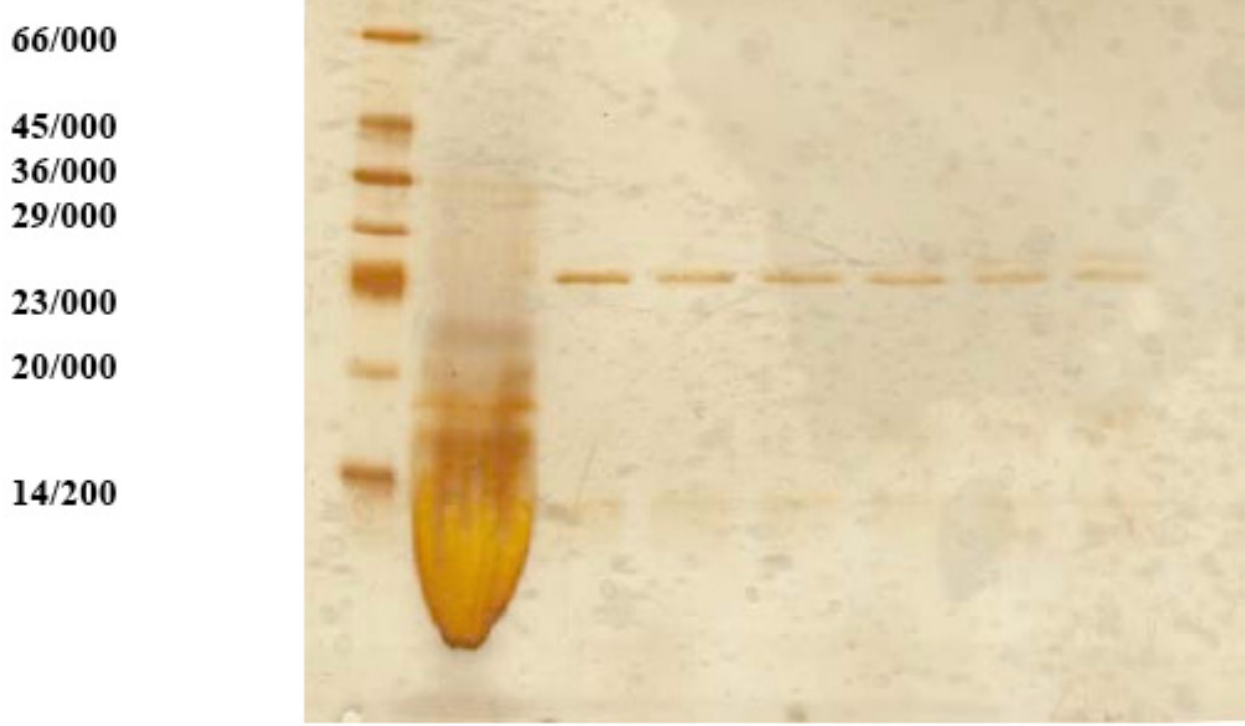

Fig. (1). Polyacrilamyde gel electrophoresis of papain. The samples in the different lanes represent: Standard (lane 1), crude latex extract (lane 2), different fractions of papain after purification by anionic exchange chromatography (lane 3-8).

(SDeS) was obtained from Merck. The concentration of the n-alkyl sulfates, used in all experiments was under the critical micelle concentration (CMC) and the critical aggregation concentration (CAC) [25, 26]. 8-Anilino-1naphthalen sulfonic acid (ANS) was purchased from Aldrich-Sigma, USA. A stock solution of ANS was prepared in minimum amount of methanol and the concentration was determined with an extinction coefficient of $5000 \mathrm{M}^{-1} \mathrm{~cm}^{-1}$ at $380 \mathrm{~nm}$ [27]. All other used reagents were of analytical grade, the highest quality commercially available.

\subsection{Solution Preparation}

The protein solution was dialyzed against buffer $(20 \mathrm{mM}$ $\mathrm{HCl}, \mathrm{pH} 2$ and $50 \mathrm{mM}$ phosphate buffer, $\mathrm{pH} 8.7)$. The extinction coefficients were used to calculate the concentration of the native protein at different $\mathrm{pH}$ values. If the initial concentration and volume of protein solution are $[\mathrm{P}]_{0}$ and $V_{0}$ respectively, and the stock ligand concentration is $[\mathrm{L}]_{0}$, then the total concentration of protein $\left([\mathrm{P}]_{\mathrm{t}}\right)$ and ligand $\left([\mathrm{L}]_{\mathrm{t}}\right)$ can be obtained by accounting for the total volume of the aliquot $\left(V_{\mathrm{c}}\right)$ added during the titration experiment [28]:

$[\mathrm{P}]_{\mathrm{t}}=[\mathrm{P}]_{0} V_{0} /\left(V_{0}+V\right),[\mathrm{L}]_{\mathrm{t}}=[\mathrm{L}]_{0} V_{0} /\left(V_{0}+V_{\mathrm{c}}\right)$.

The aliquots of the n-alkyl sulfate were injected in to the papain solution at $5 \mathrm{~min}$ intervals to allow for equilibration. Each experiment was repeated three times [24].

\subsection{Methods}

\subsubsection{Absorption Measurements}

The absorption spectra of papain were obtained with a spectrophotometer, Model Shimadzu pc 1650, with cells of one $\mathrm{cm}$ diameter. The protein concentration was determined at $0.04 \%$. Samples containing different concentrations of $n-$ alkyl sulfates were equilibrated at room temperature for 5 min before recording for absorbance measurements.

\subsubsection{Fluorescence Measurements}

Fluorescence spectra were recorded with a JASCO FP2600 spectrofluorometer. Samples containing different concentrations of n-alkyl sulfates were equilibrated at room temperature for $5 \mathrm{~min}$ before recording for tryptophan fluorescence measurements. The excitation wavelength was at $278 \mathrm{~nm}$ and the emission was recorded from 300 to 400 $\mathrm{nm}$. ANS spectra were reported between 400 and $700 \mathrm{~nm}$ with an excitation at $350 \mathrm{~nm}$. Protein concentration was 0.04 $\%$ for all experiments.

\section{RESULTS}

The $15 \mathrm{ml}$ fresh milky latex extracted from samples of C. papaya contained $121.6 \mathrm{mg} / \mathrm{ml}$ papain with 3648000 units of protease activity $/ \mathrm{ml}$. As papain is a protease of broad specificity and no specific synthetic substrate is available, casein was used as a substrate to determine the total protease activity present in the latex while the purity of papain was determined by electrophoretic and chromatographic techniques. On anionic gel electrophoresis, the protein in the latex separated as seven bands (Fig. 1). One of these proteases was identified as papain according to its mobility that was equal to that of the standard papain and its in situ proteolytic activity on polyacrylamide gel [29, 30].

\subsection{Absorbance Measurements}

Absorbance spectroscopic technique in UV region can be used to study the binding and folding-unfolding of protein initiated by surfactant. The addition of low concentrations of n-alkyl sulfates to the papain at $\mathrm{pH} 2$ and 8.7 decreases and enhances the absorption intensities respectively. The marked change in the absorbance value of the mixture at low concentrations of $n$-alkyl sulfates corresponds to the change of the conformation of the protein, i.e. the protein is folding [31]. When the hydrophobic interactions between protein and high concentrations of anionic surfactants predominate, protein will be unfolded [32]. In fact, the binding of DS of n-alkyl sulfates to cationic sites of papain increases the absorption [33].

UV-visible spectra show the effect of chain length of nalkyl sulfates on cited interactions, indicating that higher chain lengths of n-alkyl sulfates (higher hydrophobicity) increase the probability for the presence of intermediate 
(A)

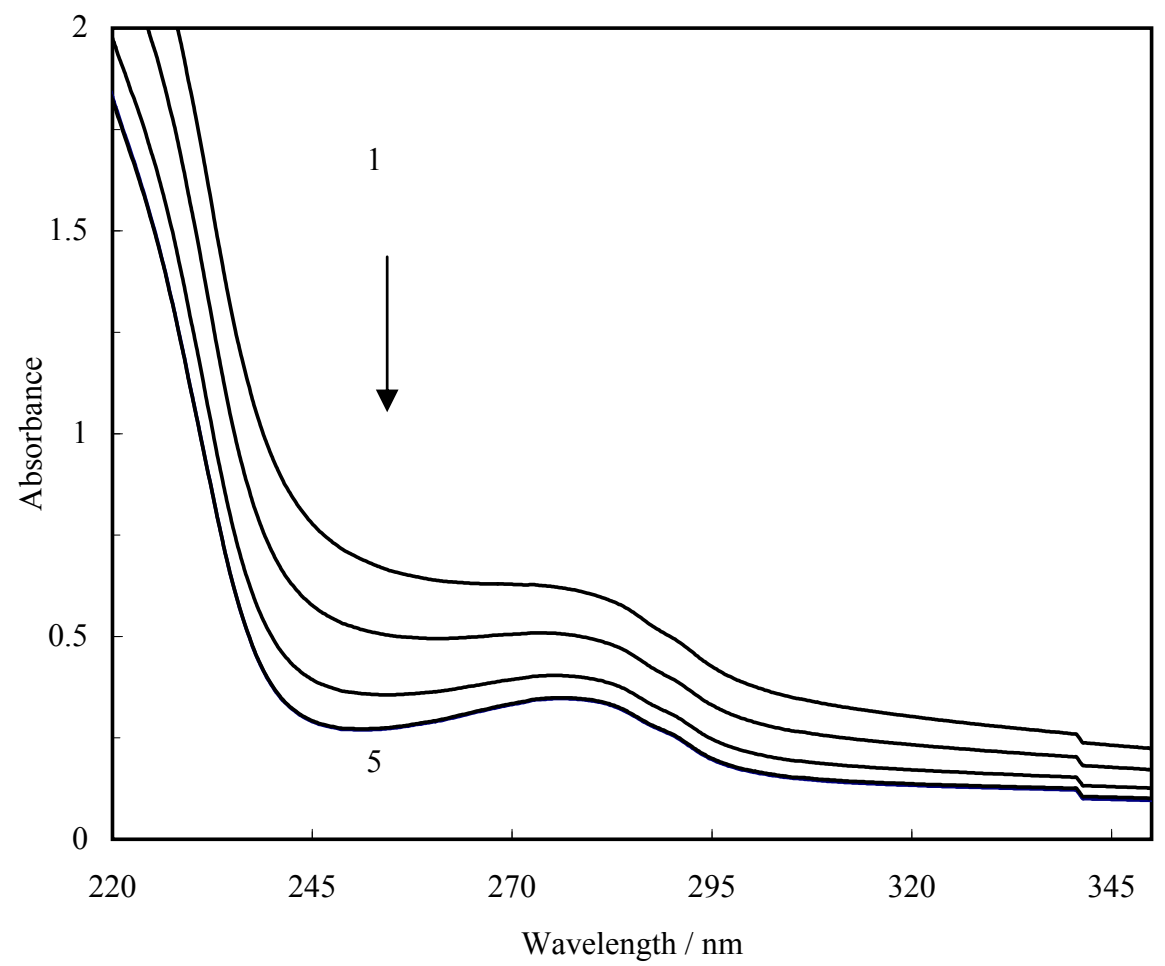

(B)

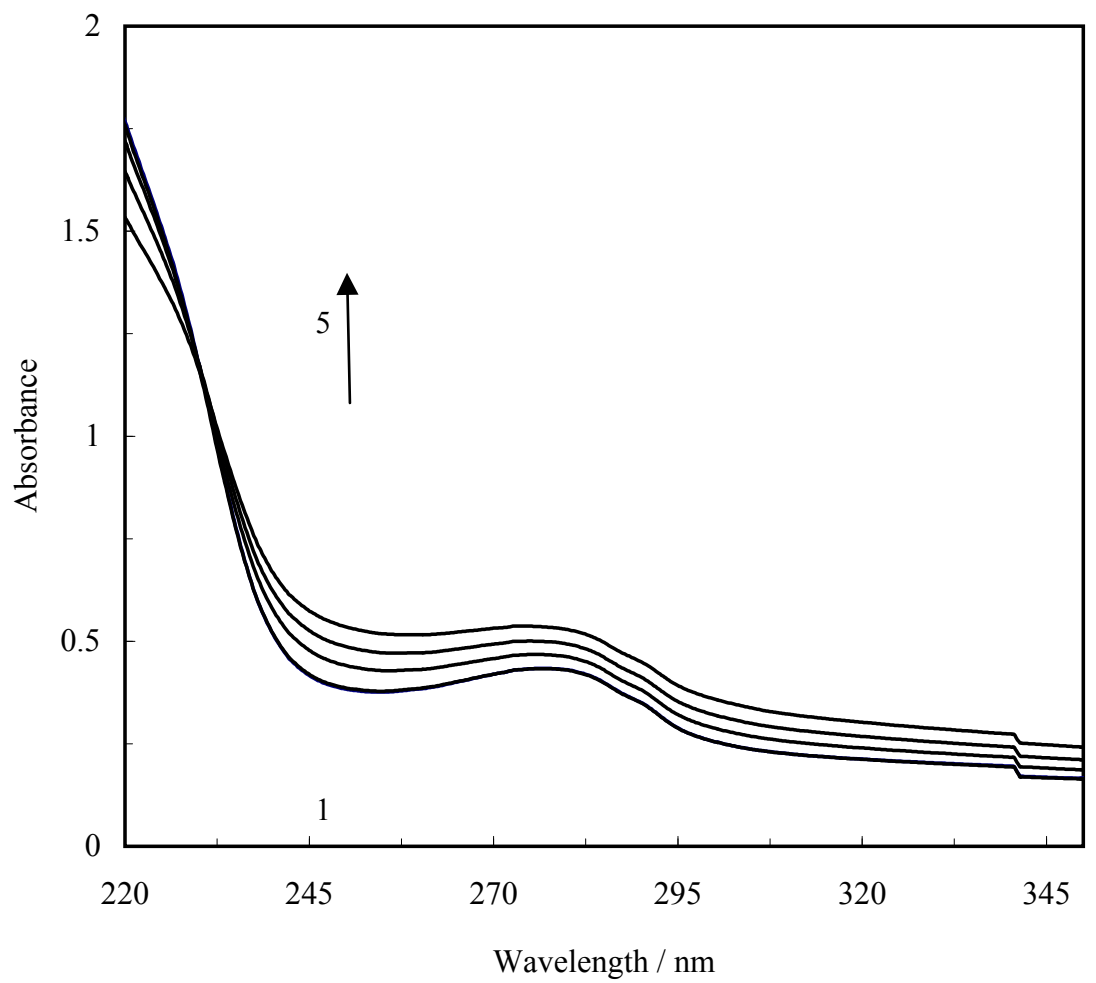

Fig. (2). (A) Absorption spectra of papain in the presence of different concentration of SDeS at pH 2. Curves 1-5 are papain upon the addition of $0,0.037,0.111,0.185,0.257 \mathrm{mM} \mathrm{SDeS}$, respectively. Inset: Plot of absorption spectra versus concentrations of n-alkyl sulfates at $\mathrm{pH}$ 2. (B) Absorption spectra of papain in the presence of different concentrations of SDeS at pH 8.7. Curves 1-5 are papain upon the addition of $0,0.611,0.68,0.781,0.882 \mathrm{mM}$ SDeS, respectively.

state. The results show that SDS is much more effective than SDeS and SOS for the formation of the intermediate state (Fig. 2). Fig. (2A, B) shows the spectra of the papain upon the addition of SDeS, at various concentrations, in the region of UV, at $\mathrm{pH} 8.7$.

\subsection{Fluorescence Measurement}

Fluorescence is an excellent probe to investigate conformational changes of proteins. Fig. $(\mathbf{3 A}, \mathbf{B})$ show the effect of SDeS on the fluorescence spectra of the acidunfolded state of papain at $\mathrm{pH} 2$ and 8.7 respectively. The 
(A)

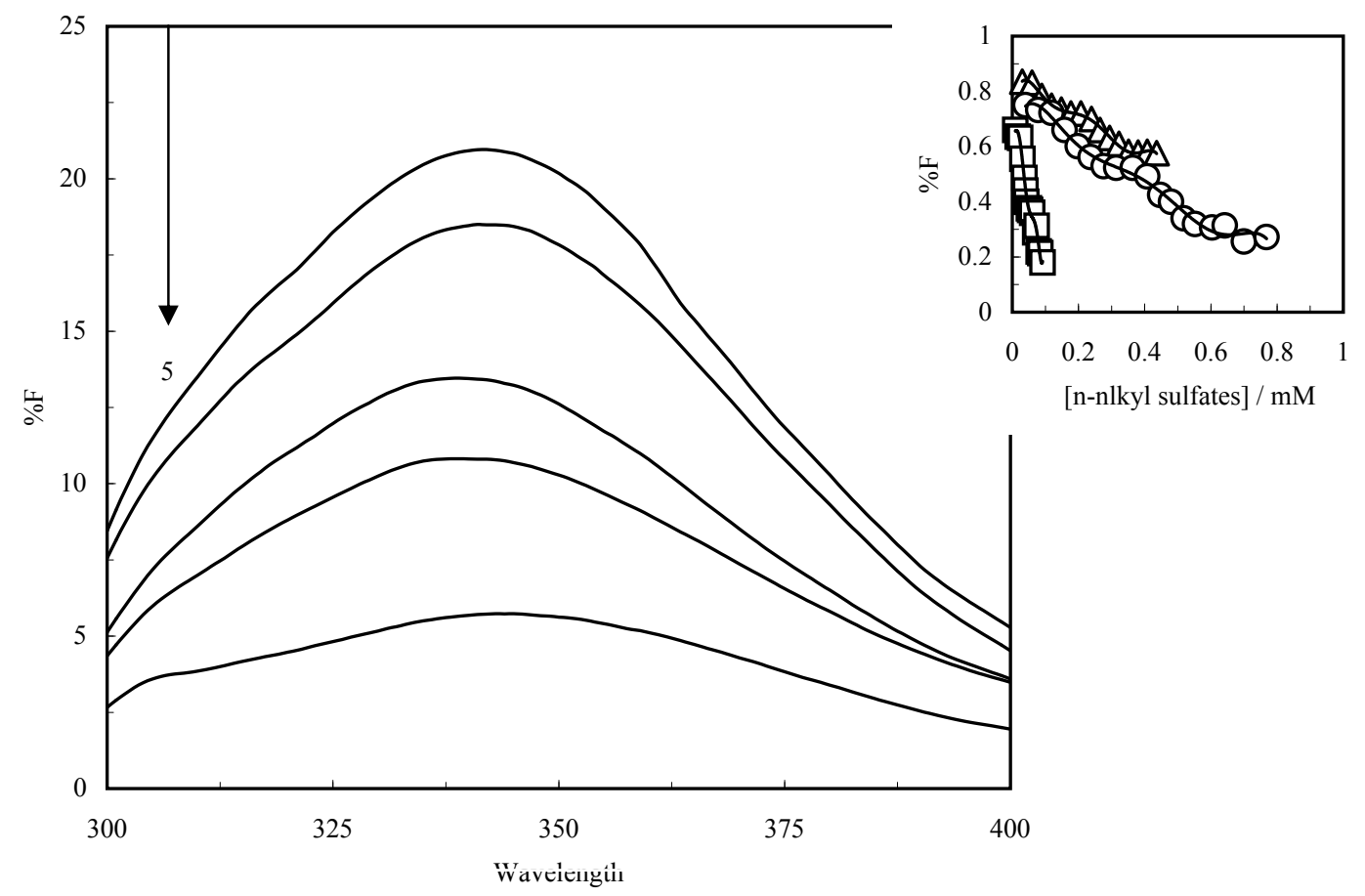

(B)

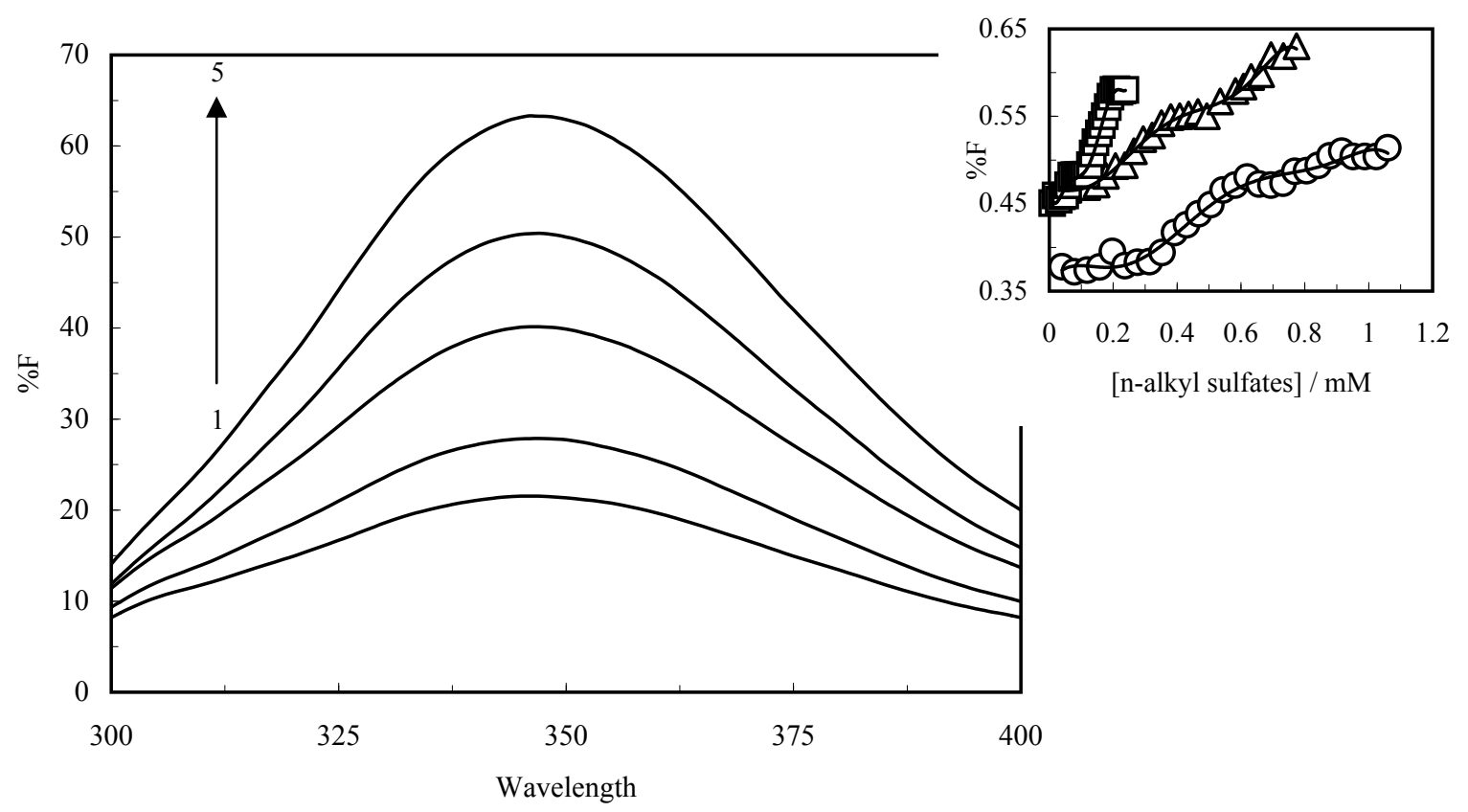

Fig. (3). (A) Fluorescence spectra of papain at different concentrations of SDeS at pH 2. Curves 1-5 are papain upon the addition of 0, 0.037, $0.576,0.915,0.981 \mathrm{mM} \mathrm{SDeS}$ at $\mathrm{pH}$ 2. Inset: Plot of intensity fluorescence versus concentration of n-alkyl sulfates at $\mathrm{pH} 2$. (B) Fluorescence spectra of papain at different concentrations of SDeS at pH 8.7. Curves 1-5 are papain upon the addition of 0, 1.425, 1.813, 2.012, 2.234 mM $\mathrm{SDeS}$ at $\mathrm{pH}$ 8.7. Inset: Plot of intensity fluorescence versus concentration of n-alkyl sulfates at $\mathrm{pH} 8.7$. SOS $(o), 20 \mathrm{mM}$; SDeS $(\Delta), 15 \mathrm{mM}$; $\operatorname{SDS}(\square) 5 \mathrm{mM}$.

inset of Fig. (3A, B) show the profile transitions of the unfolded to the molten globule state of papain induced by various concentrations of $n$-alkyl sulfates. According to Fig. $(\mathbf{3 A}, \mathbf{B})$, the addition of low concentrations of SDeS to the acid-unfolded state and native state of papain causes a decrease and enhances fluorescence intensity. The Protein showed some tendency to unfold at the presence of n-alkyl sulfates with an increasing number of buried tryptophan residues being exposed at the surface of the molecule.
However, the addition of n-alkyl sulfates to MG state at $\mathrm{pH}$ 2 shows quenched ANS fluorescence the native state as opposed to in which a similar addition leads to an increase in ANS fluorescence. Decreasing the binding affinity of the hydrophobic dye (ANS) in the presence of n-alkyl sulfates indicates that the exposure of hydrophobic region has been decreased due to the presence of n-alkyl sulfates, and, hence, the burial of the hydrophobic groups further into the interior of the molecule (data not shown). 
Sigmoidal curves - Fig. (3A, B) show the profile transitions of the MG state to the native state pathway (MG $\left.\mathrm{N}^{\prime}\right)$ and the Native to the unfolded state process $(\mathrm{N} \longrightarrow \mathrm{U})$ of papain, at various concentrations of n-alkyl sulfates in the presence of ANS. These figures also show the effects of the number of hydrophobic chains on the inflection points of the cited profiles. When the hydrophobic tail of n-alkyl sulfate becomes longer, the inflection points of the profiles decrease. These results show that the refolding and unfolding ability of papain increase according to the length of hydrophobic chains.

\subsection{Thermodynamic Analysis of Intermediate State Formation}

Fig. (3A, B) show the sigmoidal curves (drawn by a numerical analysis method, called qubic-spline in the MATLAB program, version 6.1) for the transition MG state to the native state $\left(\mathrm{MG} \rightarrow \mathrm{N}^{\prime}\right)$ at $\mathrm{pH} 2$ and transition of the native state turns to the unfolded state of papain $\mathrm{N} \longrightarrow \mathrm{U}$ ) at pH 8.7 upon the addition of n-alkyl sulfates. Papain is a small protein with a single subunit. Therefore, a two state analysis based on the pace theory was performed [31]. It is now possible to obtain the equilibrium constant $(\mathrm{K})$ for the $\mathrm{MG} \longrightarrow \mathrm{I}$ and $\mathrm{I} \longrightarrow \mathrm{N}^{\prime}$ pathways and to calculate the corresponding Gibb's free energy changes, $\Delta \mathrm{G}^{0}$, as follows:

$\Delta \mathrm{G}^{0}=-\mathrm{RT} \ln \left(\mathrm{A}_{\mathrm{obs}}-\mathrm{A}_{\mathrm{MG}}\right) /\left(\mathrm{A}_{\mathrm{I}}-\mathrm{A}_{\mathrm{obs}}\right)$

where $\mathrm{R}$ is the gas constant, $\mathrm{T}$ is the absolute temperature, $\mathrm{A}_{\mathrm{MG}}, \mathrm{A}_{\mathrm{I}}$ and $\mathrm{A}_{\mathrm{obs}}$ are the physical parameters of extinction coefficient, the percentage of fluorescence of MG, I, and any observed states, respectively. Fig. (4A, B) show the plot of $\Delta \mathrm{G}^{0}$ against total $\mathrm{n}$-alkyl sulfates concentrations ([n-alkyl sulfate $\left.]_{\text {total }}=[\text { n-alkyl sulfate }]_{\text {free }}+[\text { n-alkyl sulfate }]_{\text {bound }}\right)$. The free energies of Intermediate formation in the absence of n-alkyl sulfates, $\Delta \mathrm{G}^{0}\left(\mathrm{H}_{2} \mathrm{O}\right)$, were calculated by the leastsquare method from the following equation [34].

$\Delta \mathrm{G}^{0}=\Delta \mathrm{G}^{0}\left(\mathrm{H}_{2} \mathrm{O}\right)-\mathrm{m}[$ n-alkyl sulfate $]$

when $\mathrm{m}$ is the slope of linear curve reflecting the cooprativity and also hydrophobicity of the transition state. The m-value correlates very strongly with the extend to which the protein surface is exposed to the solvent upon unfolding [35]. Thus, for proteins that undergo a simple twostate unfolding mechanism, the extra of the surface exposed to the solvent upon unfolding is a main structure to determine the m-values and hydrophobicity. The $\Delta \mathrm{G}^{0}\left(\mathrm{H}_{2} \mathrm{O}\right)$ and m-values at $\mathrm{pH} 2$ and $\mathrm{pH} 8.7$ are tabulated in Tables 1 and 2 . The free energy values are shown as the dotted linear line in Fig. (4A, B) at pH 2 and 8.7, respectively.

It is apparent from Tables $\mathbf{1}$ and $\mathbf{2}$ that the values of $\Delta \mathrm{G}^{0}$ $\left(\mathrm{H}_{2} \mathrm{O}\right)$ and m-values of the conformational transitions induced by SOS, SDeS and SDS increase with the chain lengths of n-alkyl sulfates increase. $\Delta \mathrm{G}^{0}{ }_{1}\left(\mathrm{H}_{2} \mathrm{O}\right)$ and $\Delta \mathrm{G}_{2}^{0}$ $\left(\mathrm{H}_{2} \mathrm{O}\right)$ are for inducing of $\mathrm{I}_{1}$ and $\mathrm{I}_{2}$ at both different $\mathrm{pH}$ respectively. The inset of Fig. $(4 \mathbf{A}, \mathbf{B})$ show the $\Delta \mathrm{G}_{2}^{0}\left(\mathrm{H}_{2} \mathrm{O}\right)$ against n-alkyl sulfates concentrations that related to the second sigmoid curve in Fig. (3A , B).

\subsection{Binding of n-Alkyl Sulfates}

In this paper the possible number of binding sites "b" was also determined by using the Scatchard plot:

$1 / 1-\theta=\mathrm{K}[\mathrm{Q}] / \theta-\mathrm{Kbp}$

where $\theta$ equals $\left(\theta: \Delta \mathrm{F} / \Delta \mathrm{F}_{\max }\right) ; \Delta \mathrm{F},\left(\mathrm{F}_{0}-\mathrm{F}\right) ; \Delta \mathrm{F}_{\max },\left(\mathrm{F}_{0}-\right.$ $\mathrm{F}_{\text {saturation }}$ ); $[\mathrm{Q}]$, quencher (n-alkyl sulfates concentration); $\mathrm{K}$, affinity constant; $p$, protein concentration and $b$, number of binding sites on each protein molecule [36]. The binding set analysis would be considered as a parameter to help us study and distinguish the two different sets of binding sites which are at work during protein folding and unfolding, induced by n-alkyl sulfates. The binding of many oppositely charged surfactants to the protein molecule is supposed to cause a charge reversal of the protein - surfactant complex, compared with that of the native protein. It is also supposed that, at a specific binding ratio, the protein-surfactant complex will be uncharged, and, therefore the aggregation and precipitation of the complex are expected. Furthermore, when specific binding sites are occupied, the bound surfactant molecules may impose significant surface hydrophobicity on the complex, which may enhance hydrophobic interactions between individual proteinsurfactant complexes. The effects of various n-alkyl sulfates on the papain at $\mathrm{pH} 2$ and 8.7 show that the longer chain length increases the ability of n-alkyl sulfates to bind the protein molecule [37].

The anionic surfactant plays a variety of roles with regard to protein conformation, depending on its concentration. Surfactants have found wide applications in biology $[38,39]$. The wide spread application of surfactants in the field of biochemistry has given impetus to fundamental studies of the nature of the interactions between

Table 1. $\Delta \mathbf{G}^{0}\left(\mathrm{H}_{2} \mathrm{O}\right), \mathrm{m}-$ Value for the Intermediate States of Papain at pH 2 Upon Interaction with n-Alkyl Sulfates

\begin{tabular}{|c|c|c|c|c|c|}
\hline $\mathbf{m}_{2}$ kJ.mol. ${ }^{-1} \mathbf{M}^{-1}$ & $\mathrm{~m}_{1}$ kJ.mol. $^{-1} \mathbf{M}^{-1}$ & $\Delta \mathbf{G}^{0}{ }_{1+2}\left(\mathrm{H}_{2} \mathrm{O}\right){\mathrm{M} \mathrm{kJ} . \mathrm{mol}^{-1}}^{1}$ & $\Delta \mathbf{G}_{2}^{0}{ }_{2}\left(\mathrm{H}_{2} \mathrm{O}\right) \mathrm{kJ} \mathrm{mol}^{-1}$ & $\Delta \mathrm{G}^{0}{ }_{1}\left(\mathrm{H}_{2} \mathrm{O}\right){\mathrm{kJ} . \mathrm{mol}^{-1}}^{1}$ & \\
\hline 12.175 & 10.052 & 10.6925 & 7.4954 & 3.1971 & SOS \\
\hline 35.509 & 11.651 & 11.887 & 11.885 & 2.1701 & SDeS \\
\hline 162.7 & 109.16 & 19.7699 & 14.108 & 5.6619 & SDS \\
\hline
\end{tabular}

Table 2. $\Delta \mathbf{G}^{0}\left(\mathrm{H}_{2} \mathrm{O}\right), \mathrm{m}$-Values for Intermediate States of Papain at pH 8.7 Upon Interaction with n-Alkyl Sulfates

\begin{tabular}{|c|c|c|c|c|c|}
\hline $\mathbf{m}_{2}$ kJ.mol. ${ }^{-1} \mathbf{M}^{-1}$ & $\mathrm{~m}_{1}$ kJ.mol. ${ }^{-1} \mathbf{M}^{-1}$ & $\Delta \mathbf{G}^{0}{ }_{1+2}\left(\mathrm{H}_{2} \mathrm{O}\right) \mathrm{kJ} \mathrm{mol}^{-1}$ & $\Delta \mathbf{G}^{0}{ }_{2}\left(\mathrm{H}_{2} \mathrm{O}\right) \mathrm{kJ} \cdot \mathrm{mol}^{-1}$ & $\Delta \mathbf{G}^{0}{ }_{1}\left(\mathrm{H}_{2} \mathrm{O}\right) \mathrm{kJ} \cdot \mathrm{mol}^{-1}$ & \\
\hline 10.949 & 15.682 & 20.1816 & 11.243 & 8.9386 & SOS \\
\hline 19.763 & 10.064 & 23.1989 & 19.004 & 4.1949 & SDeS \\
\hline 76.025 & 26.155 & 18.5615 & 15.065 & 3.4965 & SDS \\
\hline
\end{tabular}


(A)

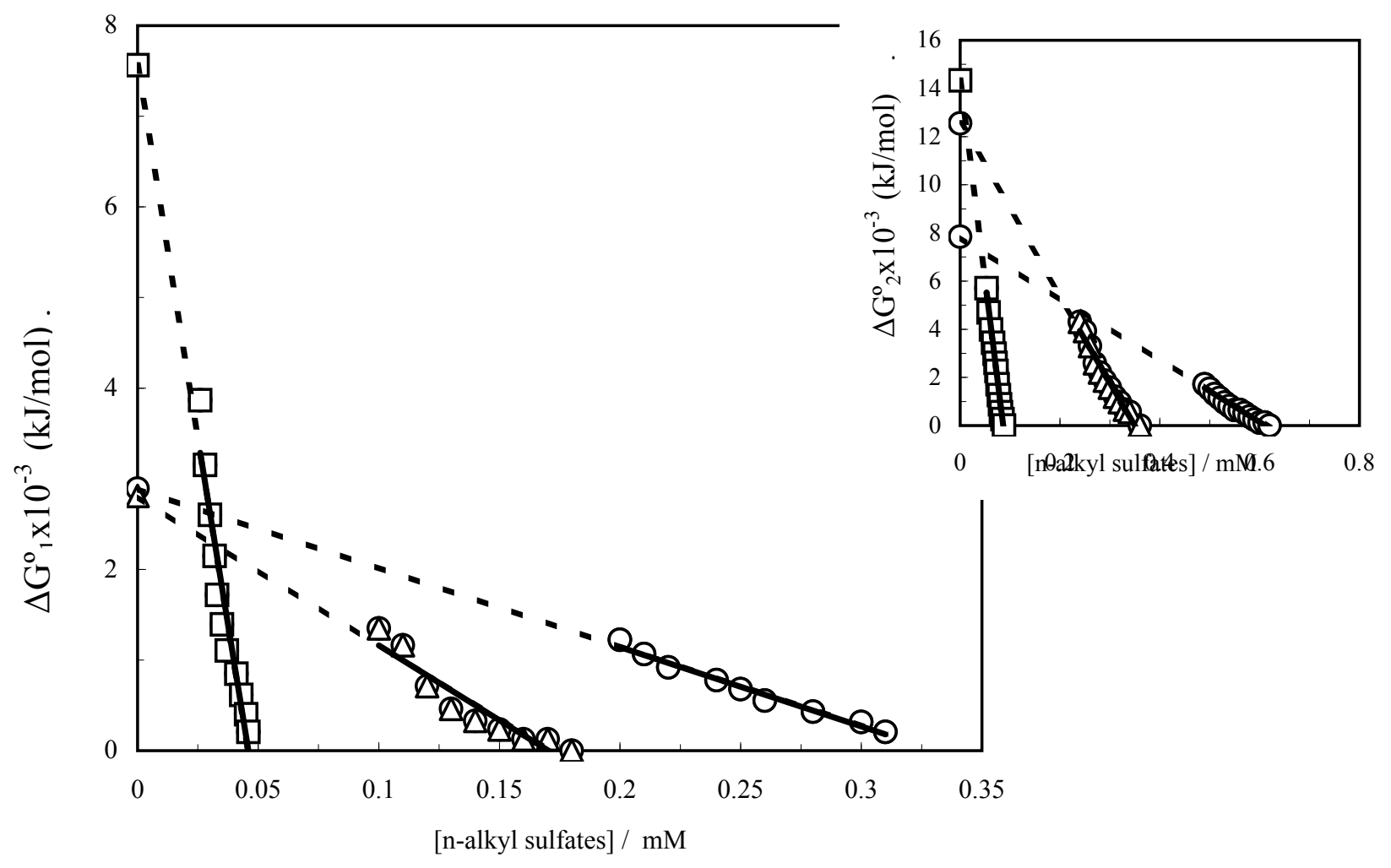

(B)

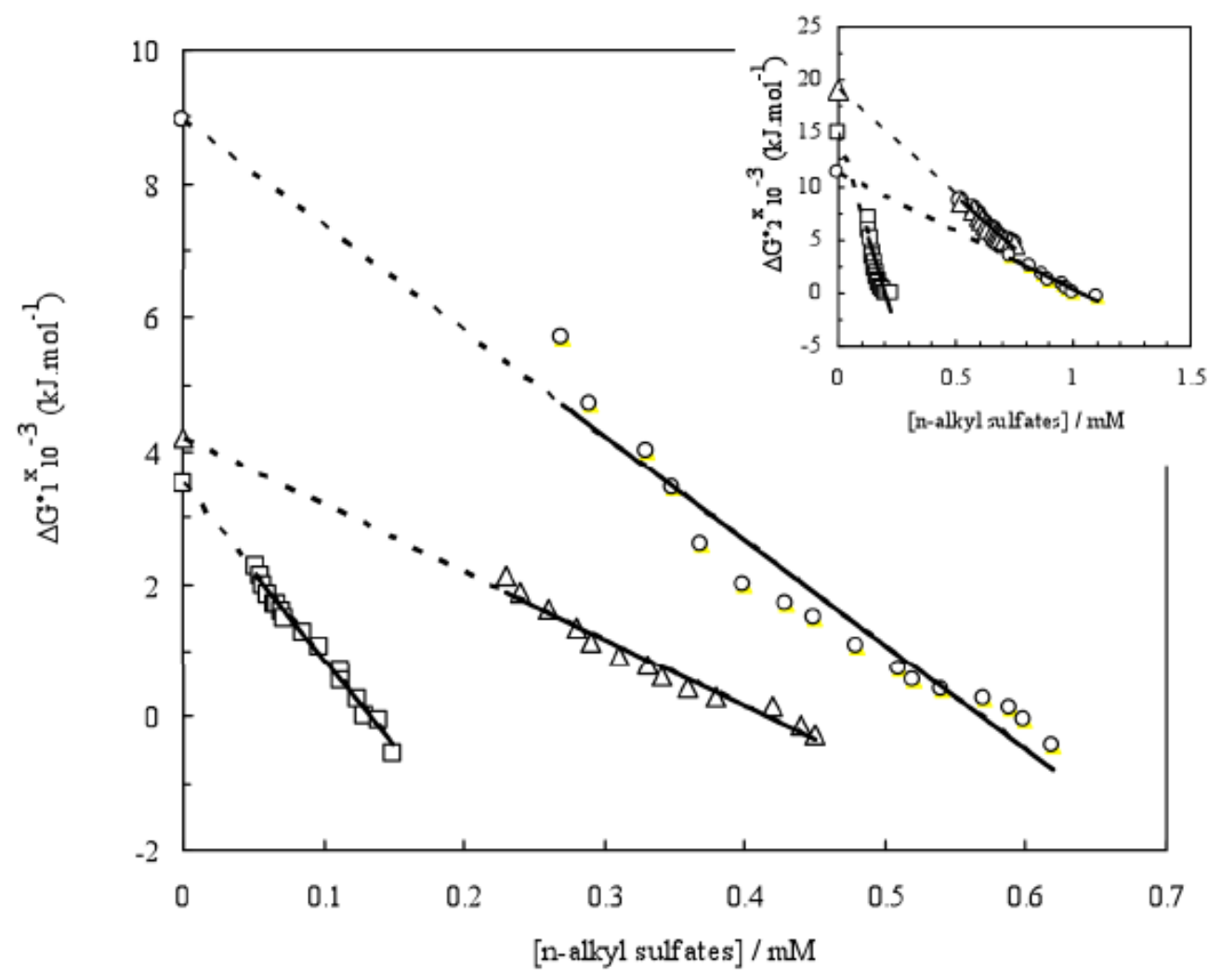

Fig. (4). (A) Free energy values $\Delta \mathrm{G}^{0}{ }_{1}\left(\mathrm{H}_{2} \mathrm{O}\right)$, versus concentrations of n-alkyl sulfates at $\mathrm{pH}$ 2. Inset: Free energy values $\Delta \mathrm{G}^{0}{ }_{2}\left(\mathrm{H}_{2} \mathrm{O}\right)$, versus concentrations of n-alkyl sulfates at $\mathrm{pH}$ 2. (B) Free energy values $\Delta \mathrm{G}^{0}{ }_{1}\left(\mathrm{H}_{2} \mathrm{O}\right)$, versus concentrations of n-alkyl sulfates at $\mathrm{pH}$ 8.7. Inset: Free energy values $\Delta \mathrm{G}^{0}{ }_{2}\left(\mathrm{H}_{2} \mathrm{O}\right)$, versus concentrations of n-alkyl sulfates at $\mathrm{pH}$ 8.7.

proteins and surface active agents in Biological phenomena such as Biological membranes and protein solubilization [40-42]. Fig. (5A, B) show the Schatchard plot of various concentrations of SDeS upon interaction with papain to determine the number of binding sites at $\mathrm{pH} 2$ and 8.7 respectively. 
(A)

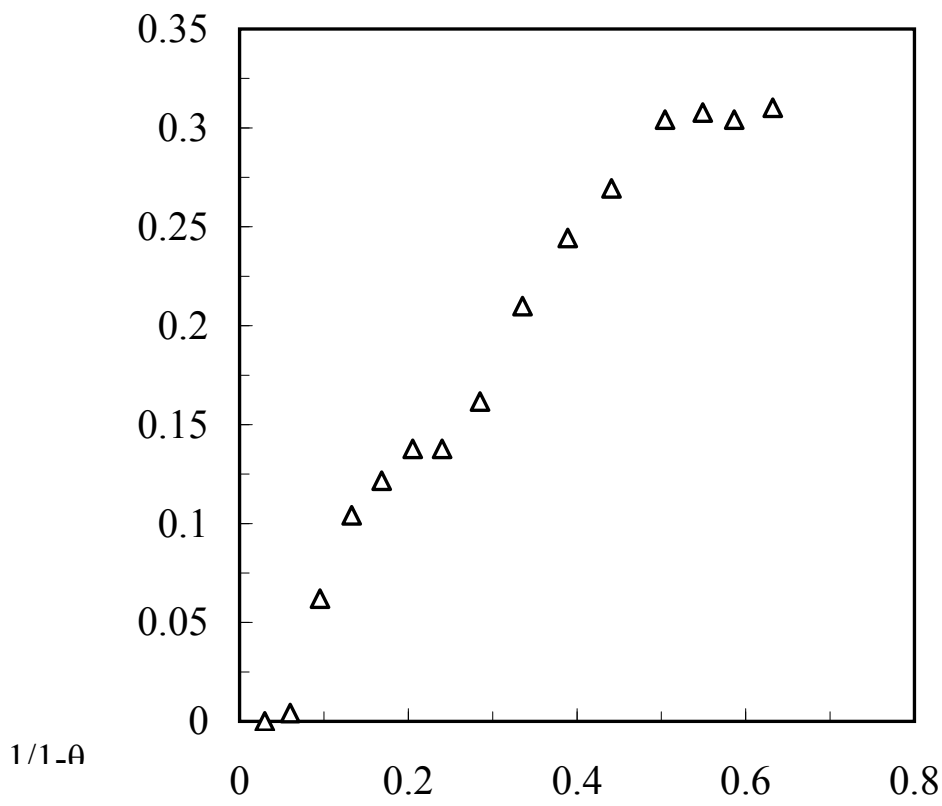

(B)

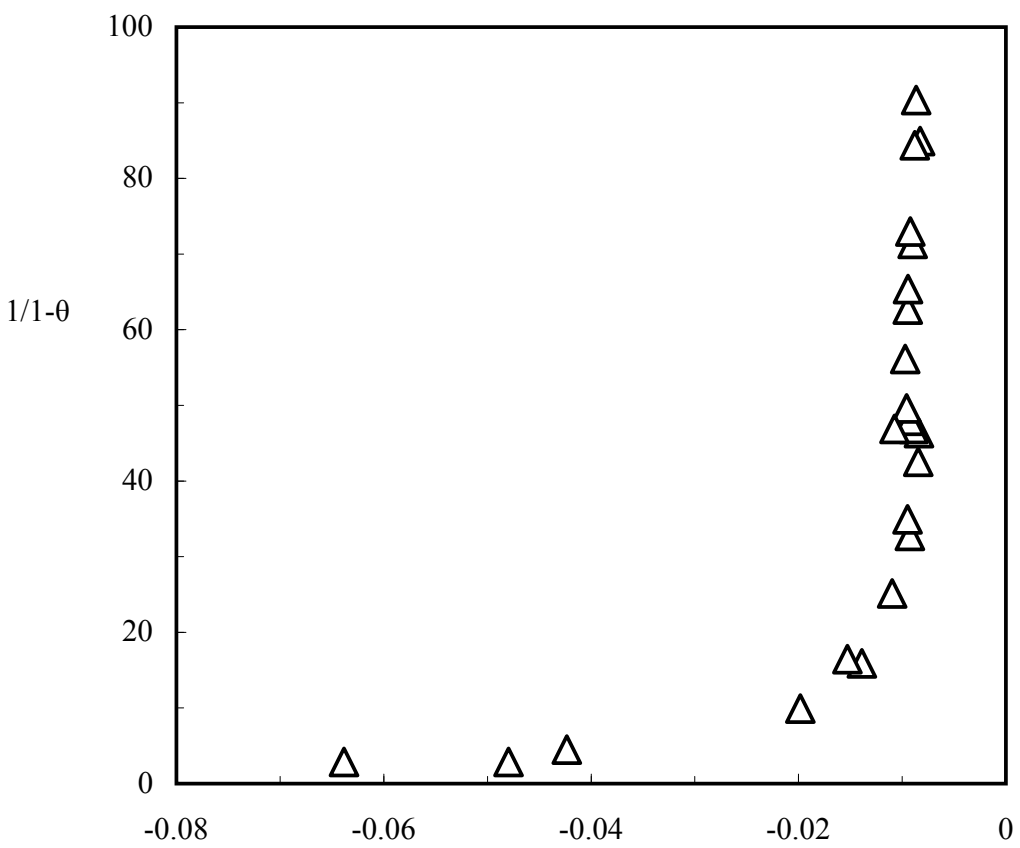

Fig. (5). Scatchard plot of papain upon interaction with $\mathrm{SDeS}$ at $\mathrm{pH} 2$ and $\mathrm{pH} 8.7$ for determination of the number of binding sites.

\section{DISSCUSION}

It has been suggested that surfactant- protein systems can be used as a model for biological membranes. Since phospholipids membranes help to stabilize the threedimensional structure of membrane proteins, the use of detergents for the reconstitution of proteins seems plausible. Further more, there are similarities in the structure of some detergents and some of the phospholipids of cell membranes. It has been shown that both the head groups and the hydrophobic tails of surfactants are important for the stabilizing of membrane proteins $[31,37,43]$. The effect of surfactants, such as n-alkyl sulfates, on protein folding and unfolding depends on the concentration of n-alkyl sulfates and protein. Anionic surfactants such as SDS, SDeS and SOS, bind to proteins in the mono-meric state and in the micellar condition. In this paper, n-alkyl sulfates were selected because of their dual electrostatic and hydrophobic interactions. These are amphiphatic compounds with a polar head and a non-polar tail group. Studies of n-alkyl sulfates with identical polar heads but different non polar tails will allow us to determine the contribution of electrostatic and hydrophobic forces to the induction of intermediate state conformation in protein denaturation pathway. Here we report the presence of intermediate state in papain denaturation pathway under acidic and native conditions in the presence of n-alkyl sulfates including SOS, SDeS and SDS. The conformation of the intermediate state is determined by the balance of charge repulsion among positive groups. When n-alkyl sulfates are added to the $\mathrm{MG}$ state of papain, in acidic condition, the shielding of intramolecular electrostatic repulsive forces in the MG state by the negative polar heads of n-alkyl sulfate binding reflects the intrinsic forces that favor the formation of the 
intermediate state. It was previously reported that two binding sets exist in protein-surfactant complexes, the first involving electrostatic interactions, and the second having a hydrophobic nature [44-48]. Once all the ionic sites are saturated, the hydrophobic contribution predominates. nAlkyl sulfates play an important role in electrostatic interactions at low concentrations, and they have a hydrophobic nature at high concentrations. Due to the nature of the MG state of papain with a positively charged surface, it was also suggested that the first interaction of a monovalent anionic surfactant is electrostatic. It is important to note that the presence of a hydrophobic moiety together with the electrostatic contribution of n-alkyl sulfates to the interaction with papain produces the intermediate state. In this manner, short range interactions between non polar groups on a protein and the non-polar tail of n-alkyl sulfates at low concentrations induce the compaction state [49-51]. Papain assumes a native conformation at $\mathrm{pH}$ 8.7. Although the anionic head of n-alkyl sulfate is an important factor determining the n-alkyl sulfate effects, we consider that the direct interaction between hydrophobic tails of n-alkyl sulfates and hydrophobic groups of protein is responsible for the n-alkyl sulfates effects. When n-alkyl sulfates interact with native state of papain at $\mathrm{pH} 8.7$, the interior hydrophobic groups of the protein are exposed to solvent, and then the polarity around the papain will decrease. This leads to stabilization of the intermolecular hydrogen binds, and, consequently, the formation of intermediate state. On the other hand, the presence of free hydrophobic tails of nalkyl sulfates (unbounded) causes the low polarity of the solvent which decreases the hydrophobic interactions stabilizing the papain, and then local hydrogen bonds are strengthened and the intermediate state is induced. SDS has different tail than SDeS and SOS. The interaction between SDS with papain at acidic condition causes the electrostatic interactions neutralized the positive charge repulsion and then short range interactions between hydrophobic tail of SDS and non-polar group of papain causes the folding of protein. It was previously reported that two binding sets exist in protein-surfactant complexes, the first involving electrostatic interactions and the second having a hydrophobic nature. Once all the ionic sites are saturated, the hydrophobic contribution predominates. Alkyl sulfates play an important role in electrostatic interactions at low concentrations and they have a hydrophobic nature at high concentrations. Due to the nature of the acid-unfolded state of papain with a positively charged surface, it was also suggested that the first interaction of a mono-valent anionic surfactant is electrostatic. It is important to note that the presence of a hydrophobic moiety together with the electrostatic contribution of $n$-alkyl sulfates upon interaction with papain produces the MG state, whereas the interaction of protein with $n$-alkyl sulfates at high concentration produces the predominant hydrophobic force that induces protein denaturation. In this manner, short-range interactions between non-polar groups on a protein and the non-polar tail of $n$-alkyl sulfates at low concentrations induce the compaction state, but at high concentrations of $n$-alkyl sulfates, the hydrophobic interactions predominate relative to the electrostatic contribution and protein unfolds.

One of the best criteria for determining protein stability is free energy in the absence of ligand, $\Delta \mathrm{G}^{0}\left(\mathrm{H}_{2} \mathrm{O}\right)$ or mvalue. $\mathrm{m}$-value for a given transition is generally interpreted as a measure of change in the solvent exposure for that transition [52] and this makes them to be useful estimates of the gross compactness of different states on the folding pathway relative to the two end-stations, the denatured state $\mathrm{D}$ and the native state N. Ligand-induced refolding is useful for understanding the mechanism of conformational stability. In particular, the m-value is important since it is a measure of the cooprativity of the folding and unfolding transitions and is proposed to be approximately proportional to the difference in solvent - accessible surface area between the folded and unfolded states [53, 54]. Tables 1 and 2 show the $\mathrm{m}$-values and $\Delta \mathrm{G}^{0}(\mathrm{H} 2 \mathrm{O})$ for the intermediate state of papain upon the addition of n-alkyl sulfates such as SOS, SDeS, SDS (below the CMC) at $\mathrm{pH} 2$ and 8.7, respectively. Tables 1 and 2 show the increase in $\Delta \mathrm{G}^{0}\left(\mathrm{H}_{2} \mathrm{O}\right)$ and $\mathrm{m}$ values that corresponds to the length of the hydrophobic chains. It will be noted that the m-value for the intermediate states induced by a low concentration of n-alkyl sulfates at $\mathrm{pH} 2$ is significantly higher than that at $\mathrm{pH} 8.7$. What is more, $\mathrm{m}$-value is a sign of cooprativity; therefore, the intermediate states induced by n-alkyl sulfates at $\mathrm{pH} 2$ are more cooperative than the intermediate state at $\mathrm{pH}$ 8.7. However, the effects of various n-alkyl sulfates on papain at $\mathrm{pH} 2$ and 8.7 indicate that the longer the chain, the higher the ability of binding n-alkyl sulfates to the protein molecule. Therefore, the quality of a solvent with various ionic strengths can determine different levels of stability and conformation of the intermediate state. The binding constant values obtained from Schatchard equation show that the binding affinity of $n$-alkyl sulfates to papain at $\mathrm{pH} 2$ is more than $\mathrm{pH}$ 8.7. Thus the intermediate structures induced by $\mathrm{n}-$ alkyl sulfates at different $\mathrm{pH}$ values are dependent on the ion quality in papain solution. On the other hand, the base of hydrophobic forces is electrostatic interactions between various kinds of ions in solution and there is a direct relationship between hydrophobicity and the stability of the intermediate states. In addition, our results show that there are two different intermediate states $\left(\mathrm{I}_{\mathrm{A}}\right.$ and $\left.\mathrm{I}_{\mathrm{B}}\right)$ induced by n-alkyl sulfates at acidic and native conditions, respectively.

\section{CONCLUSION}

The results described in this paper strongly indicate that there are different structures of intermediate states of papain induced by various concentrations of n-alkyl sulfates along refolding and unfolding pathways in two different conditions. In addition, evidence for the stabilization of the intermediate states of papain in the two different ionic solutions of n-alkyl sulfates with a hydrophobic chain has been presented. Here, n-alkyl sulfates in various conditions induced two intermediate states $\left(\mathrm{I}_{\mathrm{A}}\right.$ and $\left.\mathrm{I}_{\mathrm{B}}\right)$ with different conformations at acidic and native states, respectively. Thus, we can assume that the intermediate states in folding and unfolding pathways in various conditions have different structures. The results also indicate the appearance of higher stabilized intermediate states, which corresponds to the interaction of papain with $n$-alkyl sulphates. Therefore, our results show a direct role of hydrophobicity to the stability of the molten globule state.

\section{ACKNOWLEDGEMENT}

The financial support of the Research Council of the Islamic Azad University-Mashhad Branch is gratefully acknowledged.

\section{REFERENCES}

[1] Ghosh S. Physicochemical and conformational studies of papain/sodium dodecyle sulfate system in aqueous medium. J Colloid Surf A: Phys Eng Aspects 2005; 264: 6-16. 
[2] Edwin F, Jagannadham MV. Single disulfide bond reduced papain exists in a compact intermediate state. J Biochem Biophys 2000; 1479: 69-82.

[3] Robert AM, Dann L, Lown G. The specificity of the $\mathrm{S}_{1}{ }_{1}$ subsite of papain. J Biochem 1974; 141: 495-501.

[4] Mitchel RE, Claiken, MI, Smith ELJ. The complete amino acid sequence of papain. J Biol Chem 1970; 245: 3485-92.

[5] Mendiola SS, Arroya-Reyna A, Hernandes AA. Circular dichroism of cysteine proteinases from papaya latex. Evidence of differences in the folding of their poly peptide chain. J Biochem Biophys Acta 1992; 1118: 288-92.

[6] Sangeetha K, Emilia Abraham T. Chemical modification of papain for use in alkaline medium. J Mol Catal B: Enzym 2006; 38: 1717.

[7] Sathish HA, Kumar PR, Prakash V. Mechanism of solvent induced thermal stabilization of Papain. J Biol Macromol 2007; 24: 65-71.

[8] Watson C, Yaguchi M, Lynn KR. The amino acid sequence of chymopapain from Carica Papaya. J Biochem 1990; 266: 75-81.

[9] Taaniguchi KJ, Sasaki M. Partial purification and properties of urinary thiol proteinase inhibitors. J Biochem 1981; 89: 179-84.

[10] Bainess BS, Brocklehurst KA. A necessary modification to the preparation of papain from any high-quality latex of carica papaya and evidence for the structural integrity of the enzyme produced by traditional methods. J Biochem 1970; 177: 541-8.

[11] Baines BS, Brocklehurst K. Characterization of papaya peptidase A as a cystein proteinase of carica papaya. With active center properties that differ from those of papain by using $2.2^{\prime}$ - dipyridyl disulfide and 4-choloro-7-nitrobenzofuranozan as reactivity probes. J Biochem 1982; 205: 205-11

[12] Kimmel JR, Smith, EL. Cristallin papaim: preparation, specificity and activation. J Biochem 1954; 207: 515-31.

[13] Bines BS, Brocklehurst K. A necessary modification to the preparation of papain from any light-quality latex of carica papaya and evidence for the structural integrity of the enzyme produced by traditional method. J Biochem 1979; 177: 541-8.

[14] Barett AJ, Rawlings ND, Woessner JF. Introduction : cysteine peptidase thein clan. In: Handbook of Proteolitic Enzyme: Academic Press: Sandiego 1998.

[15] Bendall MR, lowe G. Co-operative ionization of aspartic-acid-158 and histidine-159 in Papain. J Biochem 1975; 65: 481-91.

[16] Aobegeena N, Khurshid AK, Rizwan HK. Characterization of a partially folded intermediate of papain induced by fluorinated alcohols at low pH. J Arch Biochem Biophys 2006; 341: 220-6.

[17] Edwin F, Jagannadham MV. Single disulfide bond reduced papain exists in a compact intermediate state. J Biochem Biophys Res Commun 1998; 252: 654-60.

[18] Light A, Frater R, Kimmel JR, Smith EL. Current statuse of the structure of papain : the linear sequence, active sulphydryl group and the disulfide bridges. J Proc Natl Acad Sci USA 1964; 52: 1276-83.

[19] Looze J, Bartik K, Russens V, Wintjens R, Boussard P. Structural characterization of the papaya cystein proteinases at low $\mathrm{pH}$. J Biochem Biophys Res Commun 2006; 341: 220-6.

[20] Baines BS, Brokcklehurst KA. Isolation and characterization of the four major cyctein- proteinase component of the latex of carica papaya L.reactivity characteristics towards 2,2 : dipyridil disulfide of the thiol groups of papain, chymopapain A, B, and papaya peptidase A. J Protein Chem 1982; 1: 119-39.

[21] Edwin F, Jagannadham MV. Single disulfide bond reduced papain exists in a compact intermediate state. J Biochem Biophys 2000; 479: 69-82.

[22] Balls AK, Lineweaver H, Thompson RR. Isolation and properties of cristalin papain. J Sci 1937; 86: 379-81

[23] Taaniguchi KJ, Sasaki M. Partial purification and properties of urinary thiol proteinase inhibitors. J Biochem 1981; 89: 179-84.

[24] Bainess BS, Brocklehurst KA. A necessary modification to the preparation of papain from any high-quality latex of carica papaya and evidence for the structural integrity of the enzyme produced by traditional methods. J Biochem 1970; 177: 541-8.

[25] Moller GW. Ionization characteristics of the cys-25 / His-159 interactive system and of the modulatory group of papain: resolution of ambiguity by electronic perturbation of the quasi-2mercapto pyridine leaving group in a new pirimydil disulfide reactivity prob. J Biochem 1993; 190: 289-96.

[26] Nitsawang S, Rajni HK, Pawinee K. Purification of papain from carica papaya latex: aqueous two-phase extraction versus two-step salt precipitation. J Enzyme Microb Technol 2006; 39: 1103-7.

[27] Chamani J, Heshmati M. Mechanism for stabilization of the molten globule state of papain by sodium n-alkyl sulfates: spectroscopic and calorimetric approaches. J Colloid Inter Sci 2008; 322: 119-27.

[28] Chamani, J. Comparsion of the conformational stability of the nonnative -helical intermediate of thiol-modified B-lactoglobulin upon interaction with sodium n-alkyl sulfates at two different $\mathrm{pH}$. J Colloid Interface Sci 2006; 299: 636-46.

[29] Brockhurst K, Salih E. Fresh non-fruit latex of carica papaya contains papain, multiple from of chymopapain and papaya peptidase. J Biochem 1985; 228: 525-7.

[30] Polgare L. Problemes of classification of papaya latex proteinase. J Biochem 1984; 221:555-66.

[31] Moosavi-Movahedi AA. Thermodynamics and binding properties of surfactant-protein Interactions. In: The encyclopedia of surface and colloid science. Marcel Dekker: Inc. New York 2002.

[32] Dayer MR, Moosavi-Movahedi AA, Norouzi P, Ghourchian H, Safarian S. Inhibition of human hemoglobin auto-oxidation upon interaction with sodium dodecyl sulfate. J Biochem Mol Biol 2002; 35: 364-70.

[33] Ghosh S. Conformation study of papain in the presence of sodium dodecyl sulfate in aqueous Medium. $J$ Colloids Surf B: Biointerfaces 2005; 41: 209-16.

[34] Kamiama T, Sadahide Y, Nogusa Y, Gekko K. Polyol induced molten glubole of cytochrome $\mathrm{c}$ an evidence for stabilization by hydrophobic interaction. J Biochem Biophys Acta 1999; 1434: 4457.

[35] Kuwajima K. The molten globule state as a clue for understanding the folding and cooperativity of globular-protein structure. J Protein Struct Funct Genet 1989; 6: 87-103.

[36] Moosavi-Movahedi AA, Chamani J. The characterization of molten globule state of proteins induced by surfactants. Protein structure-function relationship. In: Abbasi A, Ali SA, Eds. International Center for Chemical and Biological Sciences and HEJ Institute of Chemistry, University of Karachi: Pakistan 2005.

[37] Housoindokht MR, Chamani J, Saboury AA, Moosavi-Movahedi AA, Bahroloom M. Three binding sets analysis of a-lactalbumin by interaction of teradecyl trimethylammonium Bromide. J Bull Korean Chem Soc 2001; 22: 145-8.

[38] Reynolds JA, Tanford C. Binding of dodecyl sulfate to proteins at high binding ratio possible implications for the state of proteins in biological membranes. J Proc Natl Acad Sci 1970; 66: 1002-7.

[39] Muga A, Mantschend HH, Surewicz WK. Membrane binding induces destabilization of cytochrome $\mathrm{C}$ structure. $\mathrm{J}$ Biochem 1991; 20: 7219-24.

[40] Bathaie SZ, Moosavi-Movahedi AA, Saboury AA. Energetic and binding properties of DNA upon interaction with dodecyle trimethyl ammonium bromide. J Nucleic Acids Res 1999; 27: 1001-5.

[41] Hyakawa K, Saterre JP, Kwak JCT. The binding of cationic surfactant by DNA. J Biophy Chem 1983; 17: 175-81.

[42] Edwin F, Sharma YV, Jagannadham MV. Stabilization of molten Globule state of papain by urea. J Biochem Biophys Res Commun 2002; 290: 1141-6.

[43] Christenses H, Pain RH. Molten globule intermediates and protein folding. J Eur Biophys 1991; 19: 221-9.

[44] Nishii I, Takunaga F, Goto Y. Cold-denaturation of the molten state of apomyoglobin and a profile for protein folding. J Biochem 1994; 33: 4903-9.

[45] Hamada D, Hoshino M, Katako M, Fink AL, Goto Y. Intermediate conformational states of apocytochrome c. J Biochem 1993; 32: 10351-8.

[46] Goto Y, Fink AL. Conformational states of beta-lactamase: molten-globule states of acidic and alkaline $\mathrm{pH}$ with high salt. J Biochem 1989; 28: 945-52.

[47] Goto Y, Nishikori S. Role of electrostatic repulsion in the acidic molten globule of cytochrome c. J Mol Biol 1991; 222: 679-86.

[48] Griko YV, Privalvo PL. Thermodynamic puzzle of apo-myoglobin unfolded. J Mol Biol 1995; 235: 1318-25.

[49] Nishi I, Kataoka M, Goto Y. Thermodynamic stability of the molten globule state of Apomyoglobin. J Mol Biol 1995; 250: 223 -

[50] Kuroda Y, Kidokoro S, Wada A. Thermodynamic characterization of cytochrome $\mathrm{c}$ at low $\mathrm{pH}$ : observation process. J Mol Biol 1992; 223: 660-79.

[51] Kamiyama T, Sadahida Y, Nogusa Y, Gekko K. Polyol induced molten globule of cytochrome c: an evidence for stabilization by hidriphobic interaction. J Biochem Biophys Acta 1999; 1434: 4457.

[52] Muga A, Mantsch HH, Surewicz WR. Membrance binding induces destabilization of cytochrome c structure. J Biochem 1991; 30: 7219-24. 
[53] Bordbar AK, Saboury AA, Housaindokht MR, Moosavi-Mavahedi AA. Statistical effect to the binding of the ionic surfactant to protein. J Colloid Inter Sci 1997; 192: 415-9.
[54] Oiku S, Thimothy A. Effect of sodium dodecyl sulfate on folding and thermal stability of acid-denatured cytochrome c: a spectroscopic approach. Protein Sci 2004; 13: 2949-59.

(C) Chamani et al.; Licensee Bentham Open.

This is an open access article licensed under the terms of the Creative Commons Attribution Non-Commercial License (http:/creativecommons.org/licenses/by$\mathrm{nc} / 3.0 /$ ) which permits unrestricted, non-commercial use, distribution and reproduction in any medium, provided the work is properly cited. 